\title{
Self-reported adverse reactions in 4337 healthcare workers immunizations against novel H1N1 influenza
}

Harald Bias ${ }^{1,2,3}$, David Quarcoo ${ }^{2,3}$, Claus Meier-Wronski ${ }^{1}$, Sabine Wicker ${ }^{4}$, Joachim Seybold ${ }^{5}$, Albert Nienhaus ${ }^{6}$, David A Groneberg ${ }^{2,3^{*}}$ and Andres de Roux $x^{2,3}$

\begin{abstract}
Purpose: The use of the $2009 \mathrm{H} 1 \mathrm{~N} 1$ vaccine has generated much debate concerning safety issues among the general population and physicians. It was questioned if this is a safe vaccine. Therefore, we investigated the safety of an inactivated monovalent H1N1 pandemic influenza vaccine

Methods: We focused on the H1N1 pandemic influenza vaccine Pandemrix ${ }^{\circledR}$ and applied a self reporting questionnaire in a population of healthcare workers (HCWs) and medical students at a major university hospital.

Results: In total, 4337 individuals were vaccinated, consisting of 3808 HCWs and 529 medical students. The vaccination rate of the employees was higher than $40 \%$. The majority of individuals were vaccinated in November 2009. In total, 291 of the 4337 vaccinations were reported to lead to one or more adverse reactions (6.7\%). Local reactions were reported in 3.8\%, myalgia and arthralgia in 3.7\%, fatigue in 3.7\%, headache in $3.1 \%$.

Conclusions: Our data together with available data from several national and international institutions points to a safe pandemic influenza vaccine.
\end{abstract}

Keywords: adverse reaction, healthcare worker, immunization, novel H1N1 influenza

\section{Introduction}

Various infectious diseases play a major role in occupational health. Next to classical diseases such as tuberculosis [1], new diseases including SARS [2-4] or the novel influenza A H1N1/2009 virus [5,6] are endangering occupational health in the last years. The novel influenza A H1N1/2009 virus was first identified in Mexico and led to pandemic warning of the WHO in June 2009 [7].

Novel influenza A H1N1/2009 virus is often called "swine flu" and represents a result of the reassortment of different influenza viruses $[8,9]$. It was reported that the hemagglutinin (HA) gene of A H1N1/2009 was similar to that of swine flu viruses which are present in United States pigs since the year 1999. By contrast, the matrix protein $(\mathrm{M})$ and neuraminidase $(\mathrm{NA})$ genes are

\footnotetext{
* Correspondence: arbsozmed@uni-frankfurt.de

${ }^{2}$ Institute of Occupational Medicine, Social Medicine and Environmental Medicine, Johann Wolfgang Goethe-University, Theodor-Stern-Kai 7, 60590 Frankfurt am Main, Germany

Full list of author information is available at the end of the article
}

found in European swine flu isolates. Phylogenetic analysis of the pandemic H1N1/2009 virus shows that six genome segments stem from a triple-reassortant virus circulating in North American swine, seeded from human, avian and classical swine lineages.

Concerning the pandemic, a first outbreak of Influenza-like illness occurred in Mexico and the USA in April 2009 and the US Centers for Disease Control and Prevention reported seven cases of novel A/H1N1 influenza by this time.

By April 24 the WHO issued a health advisory on the outbreak of "influenza like illness in the United States and Mexico". Despite measures by the Mexican government against the spread of the virus, the number of confirmed cases raised to 2,099 by May 72009 [10]. One month later, on June 11, 2009, the WHO officially declared a H1N1 pandemic [11]. This was the first pandemic since the 1968 Hong Kong flu pandemic. The WHO alert level was lifted to phase 6.

\section{() Biomed Central}


Different vaccines were generated: In autumn 2009, GlaxoSmithKline produced the vaccine Pandemrix ${ }^{\circledR}$ [12]. Other vaccines were Focetria ${ }^{\circledR}$, made by Novartis and Celvapan ${ }^{\circledR}$, made by Baxter.

The safety of influenza vaccine is in the focus of research since many years [13-17]. Due to a special debate on the safety of the pandemic influenza vaccines [18], it was the objective of the present study to analyse the safety using a self reporting questionnaire approach in the acute event of a pandemic and a novel vaccine which was debated for its safety by the general population and healthcare worders (HCWs). We chose a population of healthcare workers (HCWs) and medical students after vaccination with Pandemrix ${ }^{\circledR}$ since according to German federal recommendations HCWs had a top priority for vaccination [19].

\section{Methods \\ Vaccine}

After the declaration of the pandemic, the German federal commission for vaccination (STIKO) recommended the vaccination for HCWs. The local occupational health service of the University Hospital Berlin Charité was supplied with 6000 Pandemrix ${ }^{\circledR}$ doses on October 26, 2009.

The active antigen of Pandemrix ${ }^{\circledR}$ derived from the A/ California/7/2009 (H1N1). Pandemrix ${ }^{\circledR}$ also contains an immunologic adjuvant AS03 which consists of DL- $\alpha$ tocopherol (vitamin E), squalene and polysorbate 80 . Thiomersal (thimerosal) is added as a preservative. Other components are formaldehyde, sodium deoxycholate, and sucrose [20]. The vaccine is generated in hen's eggs and therefore also contains traces of egg proteins. A single dose of the vaccine was injected by occupational physicians with the recommended dosage and vaccination procedure.

\section{Sample selection method}

In the situation of a pandemic and the acute supply of a novel vaccine which included the immunologic adjuvant AS03 and thiomersal (thimerosal), and a public debate about the safety of this vaccine, the sample selection method based on the assessment of all individuals that were vaccinated after informed consent at the occupational medicine centre of Germany largest university hospital. No specific further sample selection methods were applied.

\section{Population}

In total, $3808 \mathrm{HCWs}$ and 529 medical students were vaccinated with Pandemrix ${ }^{\circledR}$ after informed consent.

\section{Period}

The observed vaccination period began on October 26, 2009 and ended at December 30, 2009. All individuals that were vaccinated after informed consent.

\section{Self reporting questionnaire}

Applying a cross-sectional study design, a self reporting questionnaire (Tab. 1) was used that consisted of questions relating the time of the vaccination, the start of symptoms, the duration of symptoms, the consultation of a physician and the incapacity for work with duration. The symptoms included in the questionnaire are presented in Appendix 1. The self reporting questionnaires were received until 2010-01-31.

\section{Results \\ Population}

In total, $3808 \mathrm{HCWs}$ and 529 medical students were vaccinated. The peak of vaccinations was November 13 2009 with 459 vaccinations at one day (Figure 1).

\section{Self reported adverse reactions}

Overall, 291 of the 4337 vaccinated individuals returned the questionnaire and reported adverse reactions. This is a rate of $6.7 \%$. The majority of reported adverse reactions was found in the age between 30 and 39 years. (Figure 2)

The most frequently reported local site reactions were: local pain/pruritus or the sensacion of heat at the injection site in $3.8 \%$ out of the 4337 vaccinations, myalgia or arthralgia in $3.7 \%$, induration or erythema at the injection site in $2.6 \%$, lymph node swelling in $0.9 \%$, skin rash in $0.3 \%$ and ecchymosis at the injection site in $0.1 \%$ (Figure 3).

The presence of systemic adverse reactions were reported as follows: fatigue in $3.7 \%$, headache in $3.1 \%$, flu-like symptoms in $2.3 \%$, shivering in $1.9 \%$, temperature $>38^{\circ} \mathrm{C}$ in $1.3 \%$, dizziness in $1.1 \%$, increased perspiration in $1.1 \%$, gastrointestinal symptoms in $1.0 \%$, drowsiness in $0.9 \%$, insomnia in $0.7 \%$, formication in $0.3 \%$, Further some severe reportable adverse reactions were observed $(0.5 \%$, Figure 3$)$ as one case of facial nerve paralysis, one case of rheumatoid arthritic symptoms and one case of skin alteration which was reported to the local health authorities and the Paul-EhrlichInstitute.

\section{Duration of symptoms}

The mean duration of symptoms lasted 3.5 days, the maximal duration of symptoms was reported with 40 days. 


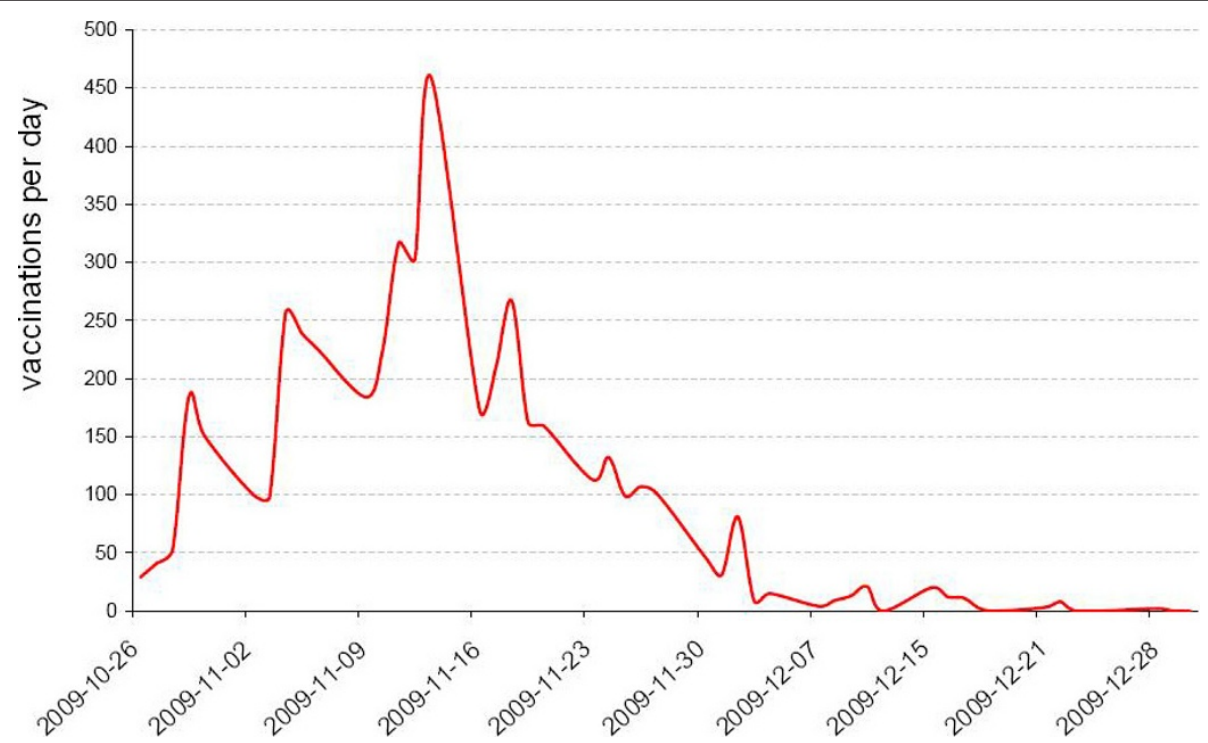

Figure 1 Daily numbers of vaccinations in the period from November to December 2009

\section{Leave of absence}

Overall, 42 HCWs $(0.97 \%)$ were not able to work due to the adverse reactions (Figure 4 ). The resulting leave of absence was 2.7 days in mean with a maximum absence of 14 days in one case. In total, there were 115 days of absence recorded.

\section{Discussion}

Personal protective equipment is important to prevent transmission of novel A/H1N1 as stated earlier by Shine et al [21]. However, vaccination is the most effective means of preventing influenza transmission and associated morbidity and mortality. It is most important to realize that an effective measure against a pandemic is to have vaccinated and well-informed health care workers.

Unfortunately, the $\mathrm{A} / \mathrm{H} 1 \mathrm{~N} 1$ vaccination coverage was extremely affected by an ongoing public discussion about potential side effects. Therefore, we analysed self reporting questionnaires concerning adverse reactions in 4337 HCWs and medical students.

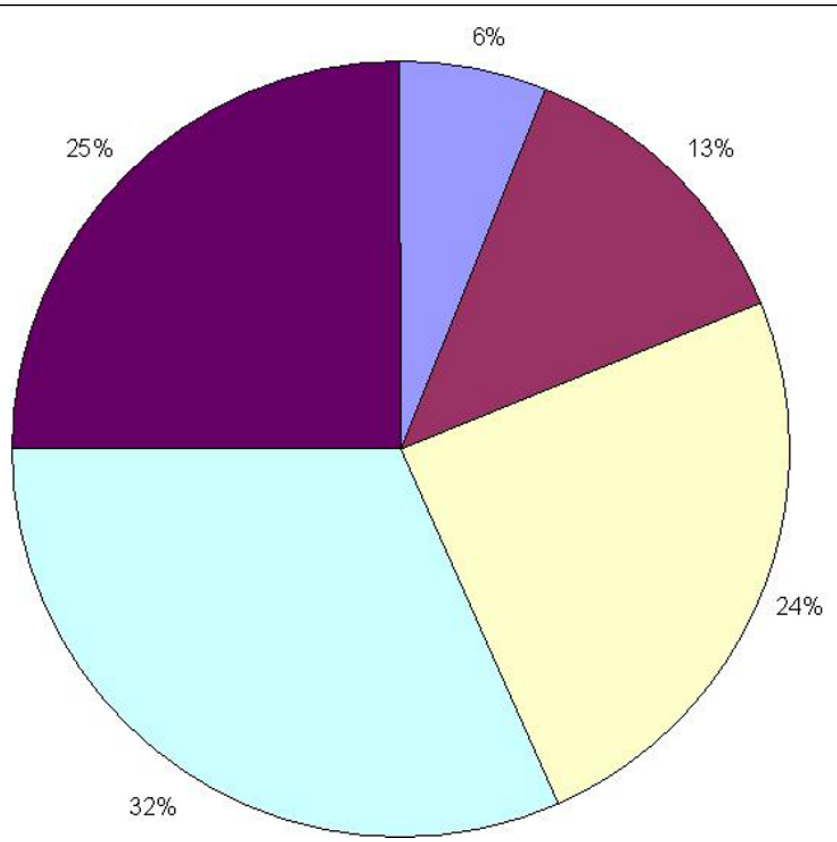

口 60 years and older

- $50-59$ years

$40-49$ years

ㅁ $30-39$ years

- under 30 years

Figure 2 Distribution of age of study participants. 

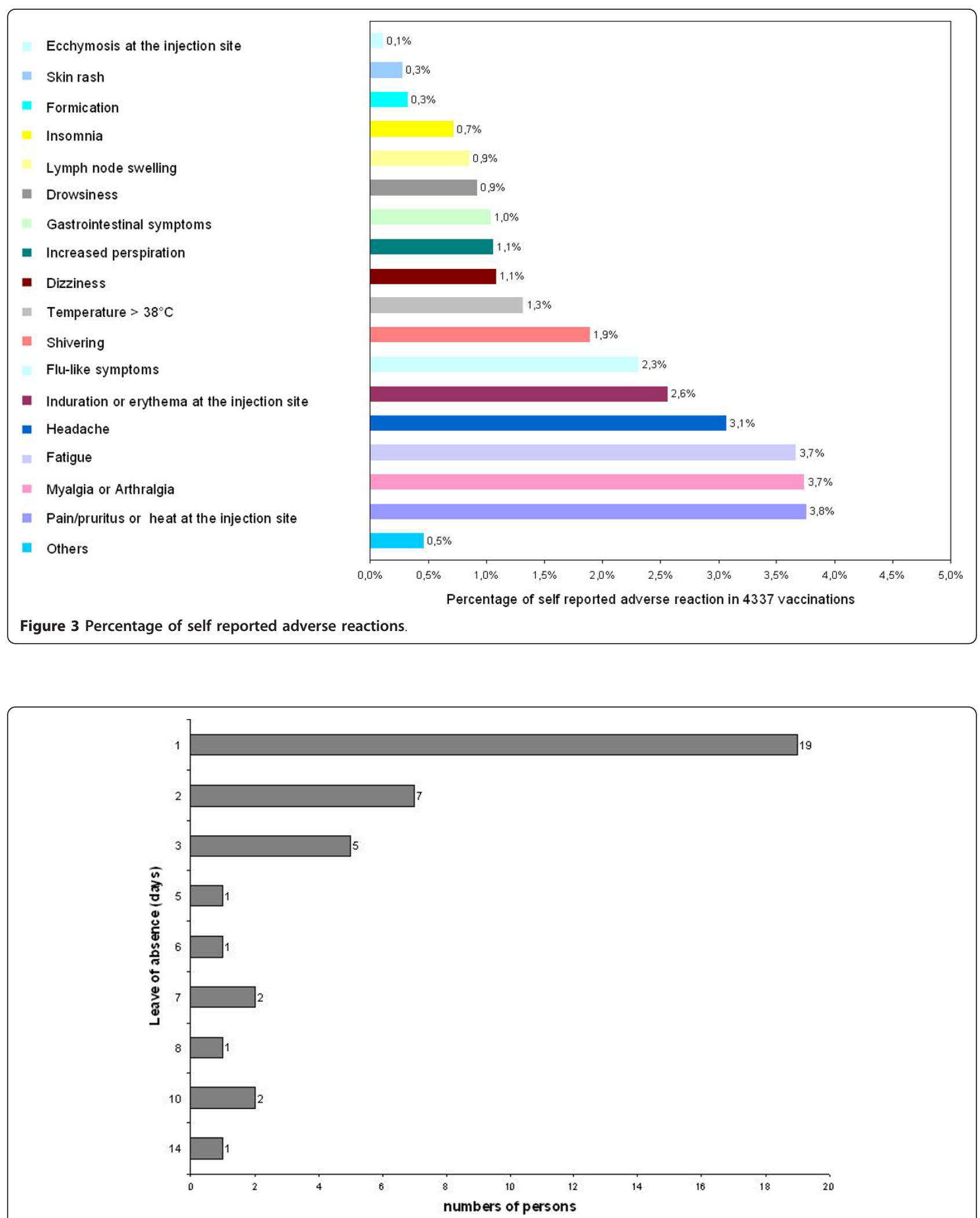

Figure 4 Leave of absence in days due to the reported adverse reactions. 
Of course, this study - that was initiated in the acute event of a pandemic and a safety discussion - has a variety of limitations. Apart from the paucity of demographic data, self reporting questionnaires are largely limited since there may be a number of individuals who do not return the questionnaire despite adverse reaction manifestation. However, there was a need to assess potential adverse reactions since the general population and the HCWs asked for data about the new vaccine. Therefore, we decided to undertake a self reporting study despite that fact that the extent of underreporting of side effects can not be examined precisely in the chosen design. It is noteworthy that with our self reporting system we found a rate of $6.7 \%$ (291 of 4337 vaccinations). This frequency differs slightly from data from other studies but points to a safe vaccine in terms of acute adverse reactions. A prospective, randomised study with 178 participants by Vajo et al. concluded that all adverse events were rare, mild, and transient. Using the vaccine Fluval $\mathrm{P}$, the most frequent reactions in this study were pain at injection site (eight cases) and fatigue for 1-2 days after vaccination (three cases) [22]. Concerning the vaccination rate we can report a rate of 4337 of about 10000 employees of the hospital. This is a vaccination rate of over $40 \%$. In a parallel study in Frankfurt/Main, the influenza vaccination rates of the HCWs of the University Hospital Frankfurt were measured. In this study, we were also able to show that the 2009 vaccination rate (seasonal influenza [40.5\%], swine flu [36.3\%]) was better than the average annual uptake of influenza vaccine in the German health care system (approximately $22 \%$ for seasonal and $15 \%$ for swine flu) [23].

In meantime, a number of studies were published that also addressed safety issues of the $\mathrm{H} 1 \mathrm{~N} 1$ vaccination in healthcare workers [24-26]. I.e. an inactivated, splitvirus, unadjuvanted $\mathrm{AH} 1 \mathrm{pdm}$ vaccine, manufactured in Japan, was given to HCWs from October 19, 2009. A retrospective cohort study was conducted and and severe adverse events were rare [24]. A recent study using monovalent vaccination (Panenza; Sanofi Pasteur, Val de Reuil Cedex, France) among HCWs in a university hospital setting in Thailand also reported a low rate of side effects. The most common adverse reaction was fatigue/uncomfortable feeling (24\%) [25].

\section{Conclusions}

It can be summarized that our data points to a safe pandemic influenza vaccine in our 4337 vaccinations. It needs to be taken into account that the use of self reporting questionnaires leads to differing results concerning the frequency of adverse reactions, of course. Therefore, this mode of reporting should be interpreted cautiously and only applied in the acute event of pandemics/novel vaccines that are administered without the usual safety testings.

\section{Appendix 1: Symptoms included in the questionnaire}

Pain/pruritus or heat at the injection site

Induration or erythema at the injection site

Ecchymosis at the injection site

Lymph node swelling

Flu-like symptoms

Temperature $>38^{\circ} \mathrm{C}$

Shivering

Headache

Fatigue

Myalgia or Arthralgia

Gastrointestinal symptoms

Insomnia

Formication (pins and needles)

Drowsiness

Dizziness

Increased perspiration (sweating)

Skin rash

Others (please specify)

\section{Acknowledgements}

The authors would like to thank the Medical Director of the Charité, Prof. Dr. $U$. Frei for his support during the H1N1 vaccination campaign and all involved HCWs.

\section{Author details}

${ }^{1}$ Occupational Medical Service, Charité - Universitätsmedizin Berlin, Free University and Humboldt University, D-14195 Berlin, Germany. ${ }^{2}$ Institute of Occupational Medicine, Social Medicine and Environmental Medicine, Johann Wolfgang Goethe-University, Theodor-Stern-Kai 7, 60590 Frankfurt am Main, Germany. ${ }^{3}$ Institute of Occupational Medicine, Charité -

Universitätsmedizin Berlin, Free University and Humboldt University, D-14195 Berlin, Germany. ${ }^{4}$ Occupational Health Service, Johann Wolfgang Goethe-

University, Theodor-Stern-Kai 7, 60590 Frankfurt am Main, Germany. ${ }^{5}$ Medical Directorate, Charité - Universitätsmedizin Berlin, Free University and Humboldt University, D-14195 Berlin, Germany. ${ }^{6}$ Institution for Statutory Accident Insurance and Prevention in the Health and Welfare Services, Department of Occupational Health Research, Pappelallee 35/37, Hamburg 22089, Germany.

\section{Authors' contributions}

HB carried out the study, participated in the analysis and drafted the manuscript. DQ participated in the analyzing and drafting process. CM-W and SW participated in the pilot study design. JS and AN participated in the design of the study and the statistical analysis. DAG and AdR conceived of the study, and participated in its design and coordination and helped to draft the manuscript. All authors read and approved the final manuscript.

\section{Competing interests}

The authors declare that they have no competing interests.

Received: 10 November 2010 Accepted: 17 August 2011

Published: 17 August 2011

\section{References}

1. Schablon A, Beckmann G, Harling M, Diel R, Nienhaus A: Prevalence of latent tuberculosis infection among health care workers in a hospital for pulmonary diseases. J Occup Med Toxicol 2009, 4:1. 
2. Pletz MW, Dickgreber N, Hagen L, Golpon H, Zabel P, Bauer TT, Welte T, Groneberg DA: [Immunisation strategies for the management of severe acute respiratory syndrome (SARS)]. Pneumologie 2007, 61:663-667.

3. von Hagen L, Pletz MW, Dickgreber N, Golpon H, Bauer TT, Zabel P, Welte T, Groneberg DA: [Pharmacotherapy of severe acute respiratory syndrome (SARS)]. Pneumologie 2006, 60:694-700.

4. Groneberg DA, Poutanen SM, Low DE, Lode H, Welte T, Zabel P: Treatment and vaccines for severe acute respiratory syndrome. Lancet Infect Dis 2005, 5:147-155.

5. Wicker S, Rabenau HF, Gottschalk R: [Influenza pandemic: Would healthcare workers come to work? An analysis of the ability and willingness to report to duty]. Bundesgesundheitsblatt Gesundheitsforschung Gesundheitsschutz 2009, 52:862-869.

6. Wicker S, Rabenau HF, Bickel M, Wolf T, Brodt R, Brandt C, Berger A, Doerr HW, Lehmann R: [Novel influenza H1N1/2009: virus transmission among health care worker]. Dtsch Med Wochenschr 2009, 134:2443-2446.

7. Trifonov V, Khiabanian H, Rabadan R: Geographic dependence, surveillance, and origins of the 2009 influenza A (H1N1) virus. N Engl J Med 2009, 361:115-119.

8. Khiabanian $H$, Trifonov $V$, Rabadan R: Reassortment patterns in Swine influenza viruses. PLoS One 2009, 4:e7366.

9. Zimmer SM, Burke DS: Historical perspective-Emergence of influenza A (H1N1) viruses. N Engl J Med 2009, 361:279-285.

10. WHO: 2009 [http://www.who.int/csr/don/2009_05_07/en/index.html], Accessed 2010-09-26.

11. Zarocostas J: World Health Organization declares A (H1N1) influenza pandemic. BMJ 2009, 338:b2425.

12. EMA: 2009 [http://www.ema.europa.eu/humandocs/Humans/EPAR/ pandemrix/pandemrix.htm], Accessed 2010-09-26.

13. Mullooly JP, Crane B, Chun C: Trivalent inactivated influenza vaccine safety in children: assessing the contribution of telephone encounters. Vaccine 2006, 24:2256-2263.

14. Kempe A, Daley MF, Crane LA, Barrow J, Chandramouli V, Beaty BL, Allred NJ, Berman S: Misperceptions regarding influenza vaccine safety for individuals with chronic medical illness. Prev Med 2007, 45:80-82.

15. Vellozzi C, Burwen DR, Dobardzic A, Ball R, Walton K, Haber P: Safety of trivalent inactivated influenza vaccines in adults: background for pandemic influenza vaccine safety monitoring. Vaccine 2009, 27:2114-2120.

16. Brown JS, Moore KM, Braun MM, Ziyadeh N, Chan KA, Lee GM, Kulldorff M, Walker AM, Platt R: Active influenza vaccine safety surveillance: potential within a healthcare claims environment. Med Care 2009, 47:1251-1257.

17. Vrijhoef $\mathrm{HJ}$, Janssen JJ, Greenberg ME: Feasibility of telemonitoring for active surveillance of influenza vaccine safety in the primary care setting in The Netherlands. J Telemed Telecare 2009, 15:362-367.

18. Schubert C: Swine flu agitates the adjuvant debate. Nat Med 2009, 15:986-987.

19. Zarocostas J: Healthcare workers should get top priority for vaccination against A/H1N1 flu, WHO says. BMJ 2009, 339:b2877.

20. EMA: 2009 [http://www.ema.europa.eu/humandocs/PDFs/EPAR/pandemrix/ H-832-en2.pdf], Accessed 2010-09-26.

21. Shine Kl, Rogers B, Goldfrank LR: Novel H1N1 influenza and respiratory protection for health care workers. N Engl J Med 2009, 361:1823-1825.

22. Vajo Z, Tamas F, Sinka L, Jankovics I: Safety and immunogenicity of a 2009 pandemic influenza A H1N1 vaccine when administered alone or simultaneously with the seasonal influenza vaccine for the 2009-10 influenza season: a multicentre, randomised controlled trial. Lancet 2010, 375:49-55.

23. Wicker S, Rabenau HF, Bias H, Groneberg DA, Gottschalk R: Influenza A (H1N1) 2009: Impact on Frankfurt in due consideration of health care and public health. J Occup Med Toxicol 2010, 5:10.

24. Igari $H$, Watanabe A, Chiba H, Shoji K, Segawa S, Nakamura Y, Watanabe M, Suzuki K, Sato T: Effectiveness and Safety of Pandemic Influenza A (H1N1) 2009 Vaccine in Healthcare Workers at a University Hospital in Japan. Jpn J Infect Dis 64:177-182.

25. Kiertiburanakul S, Malathum K, Watcharananan SP, Bunupuradah P, Piebpien P, Rujiraviroj U, Likitsinsipon W, Apivanich S, Kehachindawat P, Burakitcharoen $R$, et al: High coverage and safety of influenza A (H1N1) 2009 monovalent vaccination among health care personnel in Thailand. Am J Infect Control 2011.
26. Zhan Y, Yang Z, Li L, Ye D, Wu H, Fu R, Zhao S, Wang Y, Zhou R, Chen R: Immunogenicity and Safety of a China-Made Monovalent Pandemic (H1N1) 2009 Influenza A Vaccine in Healthcare Workers in Guangzhou, China. Jpn J Infect Dis 64:190-194.

doi:10.1186/1756-0500-4-297

Cite this article as: Bias et al: Self-reported adverse reactions in 4337 healthcare workers immunizations against novel H1N1 influenza. BMC Research Notes 2011 4:297.

\section{Submit your next manuscript to BioMed Central and take full advantage of:}

- Convenient online submission

- Thorough peer review

- No space constraints or color figure charges

- Immediate publication on acceptance

- Inclusion in PubMed, CAS, Scopus and Google Scholar

- Research which is freely available for redistribution

Submit your manuscript at www.biomedcentral.com/submit
C) Biomed Central 